\title{
Effect of guar gum supplementation on lipidic and glycidic metabolic control and body mass index in type 2 diabetes
}

\author{
Efeito da suplementação com goma guar no controle \\ metabólico lipídico e glicídico e no índice de massa \\ corporal em diabéticos do tipo 2
}

Mirela dos Santos Ourique FIGUEIREDO ${ }^{1}$

Rita de Cássia Gonçalves ALFENAS²

Sylvia do Carmo Castro FRANCESCHINI ${ }^{2}$

Maria do Carmo Gouveia PELUZIO²

Raquel Monteiro AZEREDO²

Sônia Machado Rocha RIBEIRO²

A B S T R A C T

\section{Objective}

To evaluate the effects of guar gum supplementation in the metabolic control and body mass index (BMI) of type 2 diabetic patients.

\section{Methods}

A total of 17 (12 women and 5 men) participants ingested 10 grams of fiber supplement daily for three months. Changes in $\mathrm{BMI}$ and the biochemical parameters (fasting glycemia, glycosilated hemoglobin $\left(\mathrm{HbA}_{1 \mathrm{c}}\right)$, total plasma cholesterol and triglycerides) were evaluated th the beginning and the end of the study.

\section{Results}

No changes in mean BMI ( $p=0.770)$, mean fasting glycemia $(p=0.09)$ or triglyceride levels were observed. However, significant increases in $\mathrm{HbA}_{1 c}$ levels were observed $(p<0.001)$ following the ingestion of guar gum supplements. Posterior analysis indicated that the five participants that had the highest mean fasting blood glucose and $\mathrm{HbA}_{1 c}$ levels, showed a significant reduction in their fasting glycemic levels $(p=0.03)$ at the end of the study. A significant $(p \leq 0.001)$ reduction in total cholesterol levels was observed after three months of guar gum supplementation.

\footnotetext{
1 Posto de Saúde Dr. José Vieira Serôdio. Bom Jesus de Itabapoana, RJ, Brasil.

2 Departamento de Nutrição e Saúde, Universidade Federal de Viçosa. Av. P.H. Rolfs, s/n., 36571-000, Viçosa, MG, Brasil. Correspondência para/Correspondence to: R.C.G. ALFENAS.E-mail: <ralfenas@ufv.br>.
} 
188 | M.S.O. FIGUEIREDO et al.

\section{Conclusion}

Guar gum supplementation ( $10 \mathrm{~g} /$ day) in the diet of overweight type 2 diabetics, resulting in total fiber ingestion close to $20 \mathrm{~g}$ per day, did not lead to a spontaneous reduction in body weight. The effect of guar gum on the glycidic metabolic control was inconclusive, but it was shown to be an effective dietetic strategy to reduce blood cholesterol levels.

Indexing terms: body mass index; diabetics mellitus Type 2; guar gum; metabolic control.

\section{R E S U M O}

\section{Objetivo}

Avaliar os efeitos da suplementação de goma guar no controle metabólico e índice de massa corporal (IMC) em pacientes portadores de diabetes do tipo 2.

\section{Métodos}

Um total de dezessete participantes (doze mulheres e cinco homens) receberam a suplementação diária de dez gramas do suplemento de fibra durante três meses. Alterações no IMC e nos parâmetros bioquímicos (glicemia de jejum, hemoglobina glicada ( $\mathrm{Hb}_{1}{ }_{1}$, colesterol plasmático total e triglicérides) foram avaliadas no início e ao final do estudo.

\section{Resultados}

Não foram verificadas alterações nos valores médios de $\operatorname{IMC}(p=0,770)$, glicemia de jejum $(p=0,09)$ ou triglicérides $(p=0,06)$. No entanto, foi observado aumento significativo $(p<0,001)$ dos níveis de $H b A_{1 c}$ após a ingestão dos suplementos de goma guar. Análise posterior indicou que cinco participantes que tiveram valores médios de glicemia de jejum e de $H b A_{1 c}$ mais altos tiveram uma redução significativa $(p=0,03)$ da glicemia de jejum ao final do estudo. Uma redução significativa $(p \leq 0,001)$ na concentração de colesterol total foi observada após os três meses de suplementação com a goma guar.

\section{Conclusão}

A suplementação dietética de goma guar (10g/dia) a pacientes portadores de diabetes tipo 2, com sobrepeso, proporcionando uma ingestão total de fibra próxima de $20 \mathrm{~g}$ por dia, não foi efetiva para redução espontânea do peso corporal. Os efeitos da goma guar sobre o controle metabólico da glicose foram inconclusivos, mas mostrou ser uma estratégia dietética efetiva na redução dos níveis de colesterol sangüíneo.

Termos de indexação: índice de massa corporal; diabetes mellitus tipo 2; goma guar; controle metabólico.

\section{INTRODUCTION}

Diabetes is a serious health problem and a major risk factor for cardiovascular disease in both sexes and in all adult age groups. According to the World Health Organization, in 1997 there were 143 million diabetic people worldwide 1 . Projections to the year 2025 forecast over 300 million diabetics ${ }^{1,2}$. In Brazil, diabetes mellitus affects $7.6 \%$ of the population and is the fourth leading cause of death in the nation ${ }^{3}$.

It has been demonstrated that diabetes mellitus is associated with a three to four fold increase in coronary artery disease risk ${ }^{4}$. This risk varies with glucose levels, as well as with glycosylated hemoglobin $\left(\mathrm{HbA}_{1 \mathrm{c}}\right)$. The relationship between $\mathrm{HbA}_{1 \mathrm{c}}$ and arteriosclerosis is similar in different ethnic groups 5 . The occurrence of dyslipidemia in type 2 diabetic patients may contribute significantly to accelerate coronary arteriosclerosis, the leading cause of death in these individuals ${ }^{6}$. Therefore, efficient glycemic control in the fasting state and post-prandial period, besides the maintenance of the lipid and lipoprotein profiles should be considered. Several strategies have been recommended to reach that goal, including assessment of the total daily carbohydrate intake, ingestion of a consistent amount of carbohydrate on a day-to-day basis, and a high fiber intake?

Obesity is considered one of the strongest risk factors for type 2 diabetes manifestation ${ }^{8}$. 
It has been demonstrated that weight loss leads to a better glycemic control in these pacients ${ }^{9}$. The treatment of obesity is traditionally carried out via the ingestion of hypocaloric diets ${ }^{10}$. However, the ingestion of such diets results in the activation of homeostatic mechanisms, which lead to an increase in hunger and in the basal metabolic rate ${ }^{11}$. For this reason, long-term adhesion to this type of treatment may be compromised. On the other hand, ingestion of foods that favor an increase in satiety may reduce energy intake, without increasing the hunger sensation between meals ${ }^{12}$.

Dietary fiber consumption may lead to a reduction in postprandial glycemia ${ }^{13-15}$, resulting in a meal with a lower glycemic index, lower daily total caloric intake, favoring body weight adequacy ${ }^{16-18}$. These effects favor a better control of the disease ${ }^{19,20}$. The recommended fiber intake for diabetics is similar to that recommended for non-diabetics. According to the Food and Agriculture Organization of the United Nations and the World Health Organization guidelines, fiber intake should vary between 25 and 30 grams per day ${ }^{21}$.

Dietary fiber intake should preferentially be provided by the ingestion of whole grains, fruits, and vegetables, which besides being good fiber sources are also a natural source of nutrients such as vitamins, minerals as well as having an antioxidant effect. Nevertheless, an adequate daily fiber intake is not always easily attained, due to the requirement for dietary variety ingestion and to the modern diet pattern, which is based on highly processed foods. Therefore, the ingestion of fiber supplements may become a useful alternative.

Guar gum is a polysaccharide consisting of galactose and mannose, which is obtained from vegetable seeds such as Cymepsis tetra-ganaloba, a source of pure natural fiber. It has been claimed that ingestion of soluble fibers improves glycemic control in diabetics via a reduction in the starch digestion rate, thus slowing the absorption of glucose in the small intestine. Thus the ingestion of soluble fiber can reduce the glycemic index of a meal ${ }^{18}$. Soluble fiber ingestion can also decrease blood cholesterol levels through a reduction in the absorption rate of intestinal bile acids. In this case, assuming no increase in cholesterol ingestion, a greater amount of seric cholesterol will be used to synthesize bile acids, leading to a reduction in the blood cholesterol concentration 22 .

The aim of this study was to evaluate the effects of a guar gum supplemented diet over a period of three months, on the lipidic and glycidic metabolic control and Body Mass Index (BMI) of free-living type 2 diabetic patients.

\section{METHODS}

After signing an informed consent form, a total of 20 low-income $(R \$ 240.00-R \$ 480.00 /$ month) adult patients attending a Diabetic Program for at least 5 years in the state of Rio de Janeiro (Brazil), were recruited. Eligibility criteria included: adult ( $>20$ years of age), non-smoker, type 2 diabetic, BMI >24.0 and no recent weight loss or gain ( $>3 \mathrm{~kg}$ over the previous 3 months). Three people were dropped from the study, due to difficulties in adhering to a weekly schedule of clinical monitoring. Of the final 17 participants (12 women and 5 men, aged $54 \pm 9$ years, $\mathrm{HbA}_{\mathrm{c} 1} 7.4 \pm 1.3 \%$, fasting plasma glucose $140.0 \pm 61.1 \mathrm{mg} / \mathrm{dl}$ and BMl $\left.31.12 \pm 4.32 \mathrm{~kg} / \mathrm{m}^{2}\right)$, 12 diabetics were receiving hypoglycemic agents (sulphonylureas and metformin), 2 were taking insulin, and 3 were managing their condition through diet therapy. The baseline metabolic control of the participants was as follows: fasting blood glycemia - <100mg/dl (5 participants), $\geq 100$ to $<126 \mathrm{mg} / \mathrm{dl}$ (3 participants), and $>126 \mathrm{mg} / \mathrm{dl}$ (9 participants); $\mathrm{HbA}_{1 c}-<8 \%$ (10 participants), $>8$ and $<10 \%$ (6 participants) and $>10 \%$ (1 participant)

Information about the participants' usual diet profiles was obtained using a three-day diary and a dietary record acquired in individual interviews. Based on this information, the participants' intake was calculated using the Diet 
Pro 3.0 software. The participants received nutritional and clinical counseling at least once a month before the beginning of the study, to ensure a better adhesion to regular physical activity, dietary and drug treatments, in order to control for interfering factors during the study.

This was a non-randomized clinical assay design study. Participants were provided with 10 grams of processed fiber supplement (guar gum polymer) (Purifarma, Índia) daily, for three months. Once a week, participants received packed portions of the fiber supplements, each weighing 5 grams. During these weekly visits, the participants were assessed in terms of receptivity to the study treatment and regular fiber ingestion, as well as the occurrence of any eventual side effects due to ingestion of the supplement. Diabetes management orientation, including nutritional care, was provided to the participants during the study. Dietary counseling during the study was focused on diet quality, rather than on caloric reduction. Participants were instructed to add the supplement to their lunch and dinner meals, since the analyses of their dietary intake indicated that these were the meals in which higher carbohydrate intake occurred.

Orientation related to the use of the guar gum in food preparation was provided at the beginning of the study, and during the weekly monitoring sessions. Patients were encouraged, however, to find new ways to implement guar gum in their own recipes.

The effect of guar gum supplement ingestion on the control of diabetes was evaluated based on fasting blood glucose, $\mathrm{HbA}_{1 c^{\prime}}$ total plasma cholesterol and triglycerides. These measurements were conducted after a $12 \mathrm{~h}$ overnight fast at the baseline and at the end of the study. Plasma glucose was evaluated using the glucose oxidase method and $\mathrm{HbA}_{1 \mathrm{c}}$ was measured using ionic exchange chromatography (Labtest Sistemas Diagnósticos Ltda, Belo Horizonte, MG). Cholesterol and triglycerides were measured enzymatically using kits (In vitro Diagnóstica, Itabira, MG).
The participants were only informed about the results of the biochemical parameters at the end of the study, in order to minimize any modification in dietary behavior that could affect the outcome of the study.

The anthropometric data (body weight and height) were measured at the baseline and three months after guar gum supplementation was implemented. The body weight $(\mathrm{kg})$ of the participants was measured when they were wearing lightweight gowns and no shoes. The body weight was assessed using a Filizola balance (Model 31, capacity/division: 150kg/100g). Height (m) was measured using a Filizola scale anthropometer. The body mass index (BMI) of the participants was calculated as $\mathrm{kg} / \mathrm{m}^{2}$.

All participants signed written consent forms before admission to the study and the Human Subjects Review Committee of the Federal University of Viçosa (Brazil) approved the study protocol.

Statistical analyses were performed using the Sigma Start and Epi Info software. Differences in the biochemical and anthropometric measurements before and after the dietary intervention were analyzed by paired samples T-test since Kolmogorov-Smirnov test indicated that the data presented normal distribution. The significance level was set at $p<0.05$. The results were reported as means \pm SD.

RE S U L T S

All participants adhered to the instruction of adding 5 grams of the supplement to their lunch and dinner meals daily, and reported good receptivity. This resulted in an increase in their median fiber intake of approximately 9 to 19 grams daily. No symptoms of intolerance were reported. Guar gum was added most frequently to preparations containing pumpkin, rice, oatmeal porridge, bananas, toasted manioc flour, coffee, milk, coconut flan puddings and vegetables.

The $\mathrm{BMI}$ of the participants remained constant $(p=0.770)$ during the study. The mean 
BMI values before and after the study were $31.12 \pm 4.32$ and $31.07 \pm 4.38 \mathrm{~kg} / \mathrm{m}^{2}$, respectively.

There was no significant difference $(p=0.09)$ in the mean fasting blood glucose before $(140 \pm 61.1 \mathrm{mg} / \mathrm{dl})$ and after $(159.4 \pm 56.9 \mathrm{mg} / \mathrm{dl})$ three months of dietary supplementation. However, significant increases were observed $(p<0.001)$ in the $\mathrm{HbA}_{1 c}$ levels following the addition of guar gum supplements. The mean $\mathrm{HbA}_{1 \mathrm{c}}$ level increased from $7.4 \pm 1.3 \%$ to $9.4 \pm 1.5 \%$ following the three months of the study (Figure 1).

On the other hand, when individual responses were analyzed, a significant $(p=0.03)$ reduction in fasting glycemic levels was observed in 5 ( 4 women and 1 man) diabetics after guar gum supplementation. The mean glycemic levels of these 5 diabetics dropped from $187.2 \pm 65.6 \mathrm{mg} / \mathrm{dl}$ at baseline to $120.9 \pm 49.5 \mathrm{mg} / \mathrm{dl}$ at the end of the study. Three of these participants were taking hypoglycemic agents, one was taking insulin, and one was managing the diabetes strictly with the diet. The mean baseline fasting blood glucose $(p=0.03)$ and $\mathrm{HbA}_{1 c}(p=0.02)$ values of the participants showing a positive response to gum guar supplementation were significantly higher than those of participants showing no response (Figure 2). At the end of the study, the participants showing a reduction in fasting glycemic levels presented a mean $1.82 \%$ rise in $\mathrm{HbA}_{1 \mathrm{c}}$ levels, varying between $0.5 \%$ and $2.5 \%$. The 12 participants with no positive response to the study treatment showed an increase in $\mathrm{HbA}_{1 c}$ levels of $2.03 \%$, varying between $1.2 \%$ and $3.6 \%$.

\section{Effects on blood triglyceride and cholesterol}

Total cholesterol levels decreased significantly $(p \leq 0.001)$ after three months of guar gum supplementation. Mean cholesterol level dropped from $222 \pm 49.7 \mathrm{mg} / \mathrm{dl}$ prior to dietary supplementation to $190 \pm 37.7 \mathrm{mg} / \mathrm{dl}$ following supplementation (Figure 1). Of the 17 study

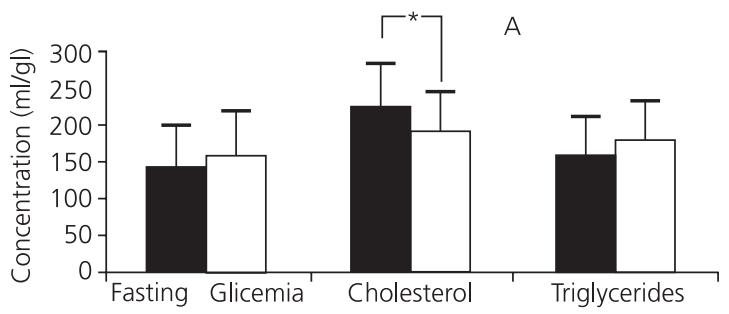

B

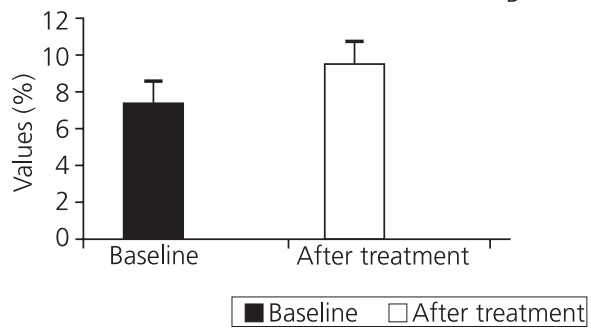

Figure 1. Mean \pm SD biochemical parameters (fasting glycemia, cholesterol and triglyceride levels $(A)$, and glycosylated hemoglobin (B)) evaluated at the baseline and three months after guar gum supplementation $(n=17)$.

Note: Cholesterol levels decreased $\left({ }^{*} p \leq 0.001\right)$ and glycosylated hemoglobin levels increased $(p<0.001)$ significantly after the study treatment.
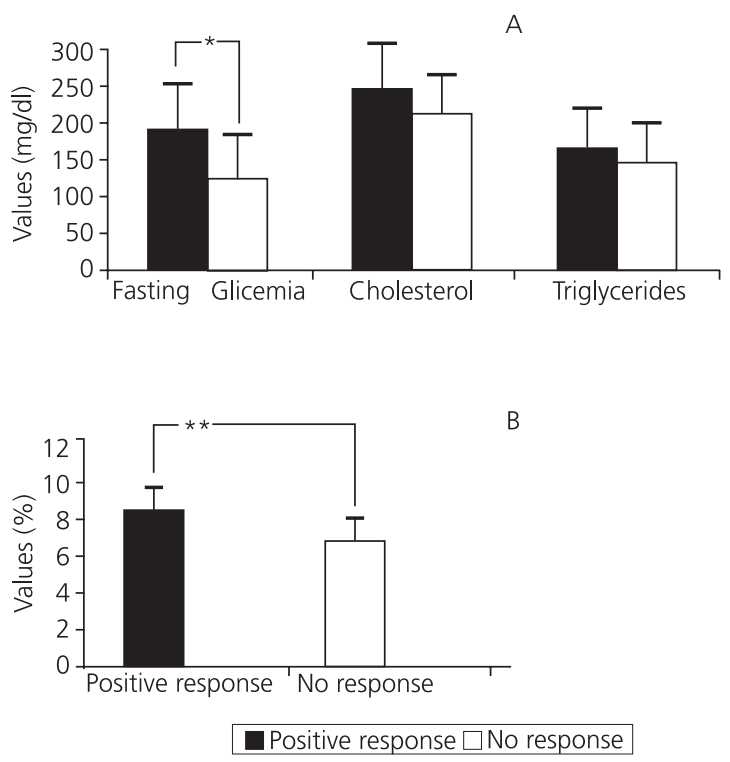

Figure 2. Mean \pm SD biochemical parameters (fasting glycemia, cholesterol and triglyceride levels (A), and glycosylated hemoglobin (B)) presented by the participants that showed positive response $(n=5)$ and those that showed no response $(n=12)$ three months after guar gum supplementation.

Note: The values for fasting glycemia ( ${ }^{*} p=0.03$ ) and glycosylated hemoglobin levels $(* * p=0.02)$ are significantly higher for the participants that presented a positive treatment response. 
participants, 16 (94\%) showed a significant reduction $(p=0.002)$ in total cholesterol levels following the three months of the study. No significant $(p=0.06)$ change in blood triglyceride levels was observed at the end of the study (Figure 1).

There was no effect of gender $(p \geq 0.20)$ or nutritional status (overweight or obesity) $(p \geq 0.05)$ on the biochemical parameters analyzed in this study.

\section{DISCUSSION AND CONCLUSION}

Due to their low income, the type 2 diabetic participants showed a limited ingestion of high fiber content foods. Analyses of their habitual intakes indicated insufficient dietary fiber intake both at lunch and dinner, meals in which there was a higher ingestion of carbohydrate rich staples such as rice, beans, wheat, pasta, and potatoes.

Since the study participants were overweight and were having difficulty in achieving body weight reductions, one of the purposes of the present study was to evaluate if the increase in fiber ingestion would lead to a spontaneous caloric intake reduction. The participants indicated that they experienced greater satiety after guar gum supplementation. However, the lack of significant changes in the BMI values suggests that there was no change in total caloric intake. This result is similar to that of another study, in which no significant alteration in body weight associated with the ingestion of guar gum enriched bread was observed ${ }^{23}$. The fact that the diabetic patients were constantly instructed to maintain their regular and habitual portion size of ingested food may have favored maintenance of the participants' body weight.

A significant reduction in blood glucose levels was observed only in 5 participants, specifically those that had the highest $\mathrm{HbA}_{1 \mathrm{c}}$ and fasting glycemia levels before beginning the study. This result suggests that the metabolic status of the diabetic patient may be a determining factor in obtaining measurable beneficial effects on such biochemical parameters, as a result of guar gum ingestion. We hypothesize that the amount of fiber supplemented $(10 \mathrm{~g} /$ day) was probably not sufficient to produce a reduction in fasting blood glucose in the other 12 study participants. There are indications that in some cases, a higher fiber intake ( $50 \mathrm{~g} /$ day) may be necessary to obtain measurable improvements in fasting glycemic levels ${ }^{15}$. The type of fiber tested in this study was not partially hydrolyzed, resulting in easy gel formation. For this reason, increasing the amount of fiber ingested per meal $(>5 \mathrm{~g}$ ) was unacceptable to the participants.

The observed increase in $\mathrm{HbA}_{1 c}$ levels is not easy to explain. This increase suggests that the amount of fiber tested in the study was not enough to control peak levels of postprandial glycemia at satisfactory levels, during the three months of the study. This hypothesis is reinforced by the fact that during the study there was no change in caloric intake or quantity and quality of carbohydrate ingested. It is also supported by the constant BMI maintained by the participants. Some investigators have indicated that since red blood cells are freely permeable to glucose, the irreversible formation of $\mathrm{HbA}_{1 c}$ from hemoglobin is directly proportional to the concentration of glucose in the blood. Therefore, $\mathrm{HbA}_{1 c}$ formation constitutes a reliable and integrated measure of the average blood glucose concentration over the life span of the red blood cells, that is, for approximately three months ${ }^{24,25}$. $\mathrm{HbA}_{\mathrm{c} 1}$ can be influenced by the glycemia before a meal, the glycemic index of the meal, the nocturnal hormonal profile and the peripheral cell absorption of glucose. It has also been suggested that $\mathrm{HbA}_{1 \mathrm{c}}$ is more closely related to pre-prandial than post-prandial blood glucose levels ${ }^{26}$.

Hence, the rise in $\mathrm{HbA}_{1 c}$ observed in this study could have occurred independently of the 
increase in fiber intake by the study participants. The observed lack of effect of guar gum on the glycemic levels of the participants differs from the result obtained in another study, in which 15 grams of gum were ingested per day for three months, leading to a reduction in $\mathrm{HbA}_{1 c}$ levels ${ }^{27}$. Besides the difference in the amount of fiber supplemented, the participants' mean $\mathrm{HbA}_{1 c}$ levels were much higher than those observed in the current study. Thus it is possible that the beneficial effect of guar gum is observed only in patients exhibiting poor glycemic control.

The reduction in blood cholesterol observed in the present study was of important clinical value, since levels above $200 \mathrm{mg} / \mathrm{dl}$ represent a greater risk for the development of cardiovascular disease ${ }^{11}$. Several studies have observed a reduction in morbidity of diabetic patients on administering cholesterol-lowering drugs. Thus, the addition of two 5-gram portions of guar gum to the daily diet is a promising dietary based strategy to treat diabetic hypercholesterolemic patients who do not benefit from standard dietary orientation. Although other studies have also observed the effect of guar gum in reducing seric cholesterol levels in diabetics ${ }^{23,27}$, more studies are necessary to evaluate its effect on the lipoprotein profile in the substitution of drug therapies. The lack of effect of guar gum on the triglyceride levels is consistent with the results obtained in other experiments ${ }^{23}$.

Considering that metabolic control is recommended in diabetics and that normal glycemic levels are not always maintained in type 2 diabetics, favoring the manifestation of dyslipidemia, the results of the present study suggest that the inclusion of guar gum in the diet could be a useful strategy in the treatment of type 2 diabetic patients presenting hypercholesterolemy. However, further studies are necessary to evaluate the effect of guar gum ingestion on dietary mineral absorption.

The beneficial effect of dietary fibers in the glycemic control of type 2 diabetics is still controversial. This study was limited by its lack of post-prandial glycemic profile monitoring. Therefore, the effect of the ingestion of 5 grams of guar gum on the glycemic levels following the midday and evening meals is not known. The ingestion of approximately 20 grams of fiber per day is not considered a useful strategy for glycemic control on a long-term basis ${ }^{28}$. Even though participants showing worse glycemic control had a reduction in their fasting glycemic levels three months after ingestion of the guar gum supplements, such an effect did not lead to long-term glycemic control, and consequently a parallel reduction in $\mathrm{HbA}_{1 \mathrm{c}}$ levels was not observed.

Regardless of the above considerations, the acceptance, adhesion, and tolerance to guar gum supplementation by the participants for three months, indicates that this strategy, along with others such as regular physical activity, adequate body weight achievement and maintenance and ingestion of a healthy diet are useful in the control of hypercholesterolemy, one of the main risk factors related to vascular complications in diabetics.

\section{REFERE NCES}

1. King H, Aubert RE, Herman WH. Global burden of diabetes: estimates for 1997. CVD Prevention. 1998; 1:243-58

2. King $\mathrm{H}$, Aubert RE, Herman WH. Global burden of diabetes, 1995-2025: prevalence, numerical estimates, and projections. Diabetes Care. 1998; 21(9):1414-31.

3. Malerbi DA, Franco LJ. Multicenter study of the prevalence of diabetes mellitus and impaired glucose tolerance in the urban Brazilian population aged 30-69 yr. The Brazilian Cooperative Group on the Study of Diabetes Prevalence. Diabetes Care. 1992; 15(11):1509-16.

4. Ginsberg HN, Illingworth DR. Postprandial Dyslipidemia: an atherogenic disorder common in patients with diabetes mellitus. Am J Cardiol. 2001; 88(6A): $9 \mathrm{H}-15 \mathrm{H}$.

5. Gerstein HC, Anand S, Yi QL, Vuksan V, Lonn E, Teo $\mathrm{K}$, et al. The relationship between dysglycemia and atherosclerosis in South Asian, Chinese, and European individuals in Canada: a randomly sampled cross- sectional study. Diabetes Care. 2003; 26(1):144-9. 
6. Garg A. Treatment of diabetic dyslipidemia. Am J Cardiol. 1998; 81(4A):47B-51B.

7. American Diabetes Association. Translation of the diabetes nutrition recommendations for health care institutions (Position Statement). Diabetes Care. 2003; 26(Suppl 1):S70-S2.

8. Pontiroli AE. Type 2 diabetes mellitus is becoming the most common type of diabetes in school children. Acta Diabetol. 2004; 41(3):85-90.

9. Norris S, Zhang X, Avenell A, Gregg E, Schmid Ch, Lau J. Long-term non-pharmacological weight loss interventions for adults with prediabetes. Cochrane Database Syst Rev. 2005; 18(2):CD005270.

10. Poston WSC, Foreyt JP. Successful managment of the obese patient. Am Farm Physician. 2000; 61(12):3615-22.

11. Rogers PJ. Eating habits and appetite control: a psychobiological perspective. Proc Nutr Soc. 1999; 58(1):59-67.

12. Holt SHA, Brand-Miller JC, Stitt PA. The effects of equal-energy portions of different breads on blood glucose levels, feelings of fullness and subsequent food intake. Am Diet Assoc. 2001. 101(7): 767-73.

13. Blackburn NA, Holgate AM, Read NW. Does guar gum improve post-prandial hyperglycaemia in humans by reducing small intestinal contact ares? Br J Nutr. 1984; 52(20):197-204.

14. Giacco R, Parillo M, Rivellese AA, Lasorella G, Giacco A, D'Episcopo $L$, et al. Long-term dietary with increased amounts of fiber-rich low-glycemic index natural foods improves blood glucose control and reduces the number of hypoglycemic events in type 1 diabetic patients. Diabetes Care. 2000; 23(10):1461-6.

15. Mcintosh M, Miller C. A diet containing food rich in soluble and insoluble fiber improves glycemic control and reduces hyperlipidemia among patients with type 2 diabetes mellitus. Nutr Rev. 2001; 59(2):52-5.

16. Spieth LE, Harnish JD, Lenders CM, Raezer LB, Pereira MA, Hangen SJ, et al. A low-glycemic index diet in the treatment of pediatric obesity. Arch Pediatr Adolesc Med. 2002; 154(9):947-51.

17. Ludwig DS, Majzoub JÁ, Al-Zahran A, Dallal GE, Blanco I, Roberts SB. High glycemic index foods, overeating, and obesity. Pediatrics. 1999; 103(3):E26.

18. Anderson JW, Smith BM, Gustafson NJ. Health benefits and practical aspects of high-fiber diets. Am J Clin Nutr. 1994; 59(Suppl 5): $1242 S-7 S$.
19. Ajani UA, Ford ES, Mokdad AH. Dietary fiber and $C$-reactive protein: findings from national health and nutrition examination survey data. J Nutr. 2004; 134(5):1181-5.

20. Schulze MB, Liu S, Rimm EB, Manson JE, Willett WC, Hu FB. Glycemic index, glycemic load, and dietary fiber intake and incidence of type 2 diabetes in younger and middle-aged women. Am J Clin Nutr. 2004; 80(2):348-356.

21. Nutrition recommendation and principles for people with diabetes mellitus. Diabetes Care. 2000; 23(1):S43-S6.

22. Gerhardt Al, Gallo NB. Full-fat rice bran and oat bran similarly reduce hypercholesterolemia in humans. J Nutr. 1998; 128(5):865-9.

23. Blake DE, Hamblett CJ, Frost PG, Judd PA, Ellis PR. Wheat brad supplemented with depolimeried guar gum reduces the plasma cholesterol concentration in hypercholesterolemic human subjects. Am J Nutr. 1998; 65(1):882-90.

24. Sacks DB, Bruns DE, Goldstein DE, Maclaren NK, McDonald JM, Parrott M. Guidelines and recommendations for laboratory analysis in the diagnosis and management of diabetes mellitus. Clin Chem. 2002; 48(3):436-72.

25. Bunn HF. Nonenzymatic glycosylation of protein: relevance to diabetes. Am J Med. 1981; 70(2): 325-30.

26. Bonora E, Calcaterra F, Lombardi S, Bonfante N, Formentini $\mathrm{G}$, Bonadonna $\mathrm{R}$, et al. Plasma glucose levels throughout the day and $\mathrm{HbA}_{1 \mathrm{c}}$ interrelationships in type 2 diabetes: implications for treatment and monitoring of metabolic control. Diabetes Care. 2001; 24(12):2023-9.

27. Kirsten R, Heintz B, Nelson K, Oremek G, Speck $U$. Influence of two guar preparations on glycosylated hemoglobin, total cholesterol and triglycerides in patients with diabetes mellitus. Int J Clin Pharmacol Ther Toxicol. 1992; 30(12): 582-6.

28. Monnier L, Lapinski $\mathrm{H}$, Colette $\mathrm{C}$. Contributions of fasting and postprandial plasma glucose increments to the overall diurnal hyperglycemia of type 2 diabetic patients: variations with increasing levels of $\mathrm{HbA}(1 \mathrm{c})$. Diabetes Care. 2003; 26(3): $881: 5$. 